\title{
Diseño como disciplina: concepto, evolución y ámbito contemporáneo
}

Sebastián García Garrido ${ }^{1}$

\section{Resumen:}

La presencia del diseño como disciplina transversal, en gran parte de las actividades y proyectos emprendidos desde otras áreas ha llegado a ser un hándicap para su consideración como área de conocimiento autónoma en el sistema universitario y superior del diseño, y en la realidad profesional.

Nace el concepto diseño en la Florencia del Renacimiento, referido al desarrollo gráfico de la idea que sustenta la creación en las tres nobles artes y posteriormente en todos los ámbitos, que incluyen el desarrollo de intangibles. Ante la necesidad de este perfil profesional especializado, en las Reales Fábricas, en 1775 Carlos III crea la primera escuela de diseñadores del mundo, para abastecer a estas primeras fábricas de producción en serie.

La relevancia del Diseño trasciende el ámbito profesional y económico para convertirse en un fenómeno que afecta a todos los aspectos de nuestra sociedad, y en conclusión requiere una disciplina autónoma, diferenciada de Dibujo en el ámbito artístico, que rige y lastra su desarrollo en el ámbito universitario de educación superior, fuera del catálogo de áreas del Consejo de Universidades.

Palabras clave: idea, diseño, dibujo, área de conocimiento, disciplina.

\section{Design as a discipline: concept, evolution and contemporary scope}

\section{Abstract}

The presence of design as a transversal discipline, in large part of the activities and projects undertaken from other areas, has become a handicap for its consideration as an independent area of knowledge in the university and higher design system, and in professional practice.

The concept of design in Florence of the Renaissance was born, referring to the graphic development of the idea that sustains creation in the three noble arts and later in all areas, which include the development of intangibles. Faced with the need for this specialized professional profile, in the Royal Factories, in 1775 Carlos III created the first school of designers in the world, to supply these first production in series.

The relevance of Design transcends the professional and economic sphere to become a phenomenon that affects all aspects of our society, and in conclusion it requires an autonomous discipline, differentiated from Drawing in the artistic field, which governs and curtails its development in the field university education, outside the catalog of areas of the Spanish Council of Universities.

Keywords: idea, design, drawing, academic-scientific area, discipline.

1 Catedrático de Universidad. Escuela de Ingenierías Industriales. Universidad de Málaga. 


\section{Particularidades como disciplina}

Los precedentes y evolución del Diseño, como disciplina profesional y académico-científica, se han considerado necesario recoger en un documento que sea referencia para la promoción de su conocimiento, investigación y desarrollo del trascendental protagonismo que tiene en nuestra sociedad. Esta misión se nos encomienda desde la coordinación ${ }^{2}$ de Transferencias.Design Málaga 2018, que celebraba en Málaga su tercera edición el pasado octubre. Por su parte, el comisario de este número conmemorativo, de la primera revista académico-científica española sobre Diseño, ha considerado que este documento debería integrarse entre sus contenidos.

La disciplina del diseño tiene un hándicap, a nivel internacional, que le impide desarrollar todo su potencial, debido precisamente a su competencia en todos los ámbitos de nuestra sociedad. Su carácter transversal le incorpora en las necesidades de innumerables disciplinas. Pero esta implicación no se corresponde con la colaboración habitual de diseñadores en proyectos, que no sean orientados directamente a la creación gráfica, de producto o cualquiera de sus especializaciones. Sin embargo, en su ya considerable experiencia, diseño viene siendo considerado en su competencia para desarrollar estrategias o ideas en cualquiera de sus ámbitos. Especialmente, en el sector servicios y las funciones de las administraciones públicas, los diseñadores vienen proyectando una serie de conceptos, actividades, escenarios de futuro, respuestas corporativas y los detalles que determinarán la comunicación en su sentido más amplio. Son profesionales de la creatividad más avanzada, y la consideración de su competencia, en la creación de las ideas, coincide por otra parte con el significado que se requería cubrir con el nacimiento del término diseño, cuando se crea en el Renacimiento italiano. No obstante, las empresas y administraciones tardarán en asimilar esta afinidad, de manera generalizada, aunque cada día más corporaciones admiten y basan su gestión, de la revalorización corporativa, en el diseño y la comunicación integrada en todas las competencias que representan.

La implicación del diseño, en prácticamente todas las disciplinas, es muy superior a otras materias transversales, afines a unos ámbitos más limitados como pueden ser la lengua, lengua extranjera, las matemáticas, o lenguajes y ciencias de la computación, que se consideran, por el contrario, parte esencial de esa colaboración interdisciplinar sin la que hoy es difícil innovar. En los estudios, del ámbito empresarial y económico, no se ha considerado la necesidad de conocer la implicación del diseño en este ámbito, y el diseñador es un mero abastecedor de suministros. Por consiguiente, no se aprecia su papel protagonista en la empresa, por parte de la mayoría de sus responsables, que no advierten el alcance de su potencial innovador y competitivo. 
Esta situación del diseño hoy viene condicionada por su escasa consideración en el sistema administrativo oficial, en el ámbito universitario y de los estudios superiores, como disciplina en sí misma, pues viene siendo una parte de la denominada área de Dibujo ${ }^{3}$. Por lo que el primer paso para liberar su desarrollo supondría la creación de un área de conocimiento propia en el catálogo del Consejo de Universidades. Una consideración que regularía la consideración en los programas oficiales de investigación y desarrollo, los perfiles de las plazas de profesorado que resolvería el problema actual de la competencia que tiene cualquier titulado genérico en Bellas Artes para impartir asignaturas de grado superior en el campo del diseño. Otra consecuencia especialmente grave es la inexistencia de criterios propios para valorar el currículo en este campo, no sólo en los concursos y acreditaciones a plazas de profesorado, sino también a la concesión de sexenios que reconozcan la actividad investigadora, y a su plena consideración en la oferta y evaluación de convocatorias de proyectos y líneas de investigación.

Este área de Dibujo, en la que nos encontramos adscritos en el ámbito universitario, se compone mayoritariamente de personal que desarrolla su docencia-investigación en estudios de Bellas Artes, un vínculo que puede ser muy beneficioso en cuanto a simbiosis creativa pero que, en la práctica, condiciona el desarrollo autónomo de una disciplina que requiere una visión completamente diferente ${ }^{4}$. Una prueba de ello está en la separación de los miembros del área de Dibujo dedicados al ámbito del arte y del diseño, en las dos universidades en que su mayor número lo permite. En la Complutense de Madrid se denominan departamento de Dibujo y Grabado, y departamento de Diseño e Imagen. En la Universidad de Barcelona se han unido los dos departamentos existentes, Dibujo con Diseño e Imagen, para constituir un solo departamento (denominado Artes Visuales e Imagen) con cuatro secciones: Arte y Cultura Visual; Procesos Artísticos de Edición; Producción de Arte Contemporáneo; y Diseño.

Sin embargo, el protagonismo del diseño no sólo está en la sociedad y la riqueza de un país sino que es evidente en la propia actividad y concepto de la creación artística contemporánea, y se aprecia claramente en las nuevas titulaciones y asignaturas de las universidades privadas que se han venido creando en España buscando la propuesta más competitiva en el panorama universitario existente.

Esta consideración oficial, y práctica en consecuencia, de no ser considerado el diseño una disciplina académico-científica como el resto, en el catálogo oficial, difiere por países, y en pocos casos está realmente considerada.

3 Una autonomía disciplinar que, en cambio, tienen ámbitos afines como Pintura y Escultura, tan unidas hoy, entre sí y con otras manifestaciones incluso propias del diseño, en lo que es la práctica artística. Mucho más integradas, en cuanto a lenguajes y procedimientos, poseen áreas de conocimiento propias. Mucho más considerada está la Arquitectura, como área afín que ha venido formando parte de las consideradas artes clásicas, y que incluso se divide en áreas de conocimiento especializadas como: Composición Arquitectónica, Construcciones Arquitectónicas, Urbanística y Ordenación del Territorio, o Proyectos Arquitectónicos. En el caso de otras disciplinas transversales como la Historia existen diez áreas diferenciadas en el catálogo oficial.

4 Esta dificultad para desarrollar la disciplina en un área afín, pero mayoritariamente compuesta por miembros del ámbito artístico, entre quienes a veces se da un cierto recelo, ante el potencial del diseño también en el arte contemporáneo. Una realidad actual en las tres facultades de Bellas Artes existentes en Andalucía, que contrasta con la denominación y composición de los títulos de grado que las universidades privadas han propiciado para atender a la demanda profesional más competitiva, es que aún no exista el Grado en Diseño en el ámbito universitario andaluz, más que en lo referente al Diseño Industrial y desarrollo del Producto en las escuelas de Ingeniería. Diseño, en la teoría, podría ser perfectamente compatible con un área denominada Dibujo, si la gran mayoría de sus miembros no la restringen al ámbito meramente artístico. Muestra de la grave situación, de no contar con área de conocimiento propia, es la respuesta en la intervención de un miembro del tribunal de habilitación a plaza de catedrático de universidad, compuesto por siete catedráticos de esta área de conocimiento (Madrid 2005): "usted tiene muchos méritos en Diseño, pero no se le pueden valorar porque el diseño es una frivolidad". Así me descalificaron, aún teniendo más sexenios de investigación que el resto de candidatos, y eludir entrar en comparar cada apartado del currículum. 
Si una característica especial distingue a esta disciplina del resto, es la integración e interrelación que mantiene con todas ellas prácticamente. Lo que le confiere una falta de concreción o autonomía, que la hace compleja y difusa. Causa que le permite, por una parte, ser una disciplina humanizante que engloba de forma natural las capacidades y valores más específicamente humanos, tanto conscientes como del subconsciente. Por otro lado, le proporciona, desgraciadamente, que no sea considerada como disciplina troncal y básica, teniendo poca valoración, tanto en los diferentes planes de estudio, como en la concepción tradicional que se tiene de ella. Esto es una rémora de una educación en que priman los conocimientos concretos y estables, fruto del predominio racional sobre el creativo, la intuición y lo emocional ${ }^{5}$.

\section{Origen y definición profesional y académica}

El diseño nace en la Prehistoria como recurso funcional -práctico y comunicacional-y estético. Sin embargo, un concepto o disciplina no existe hasta que adquiere un nombre específico. El origen del término diseño, aunque se atribuye a Giorgio Vasari, como fundador de la primera academia de artes de la historia, que denomina Accademia delle Arti del Disegno, se utiliza por primera vez en el tratado de pintura de Cennino Cennini escrito a finales del siglo XIV (c. 1390) $)^{6}$. Se trataba de una variante del término lineamenta ${ }^{7}$, que hacía referencia a un croquis o dibujo explicativo, lo que conocemos como plano o dibujo descriptivo de un concepto previamente resuelto. Disegno, en cambio, hace referencia a la idea, que a través de un boceto o proyecto configuraba las características del resultado del proceso de creación. Diseño sigue siendo hoy el resultado de un nuevo concepto o realidad, como significado básico. Mientras en español ${ }^{8}$ se asimiló el nuevo término, en italiano, sin embargo, se popularizó el uso y terminó haciendo referencia a lo que nosotros entendemos por dibujo, por lo que emplean habitualmente el vocablo design en inglés, excepto para el diseño industrial: disegno industriale.

Si para Cennino Cennini el fundamento del arte son dibujo y color, Vasari en 1550 define el diseño como origen y fundamento de las tres nobles artes (pintura, escultura y arquitectura) aludidas también como artes del diseño. Para este último, el diseño posee una doble acepción, como idea o concepto, y como manifestación gráfica de la misma. La Academia de las Artes del Diseño ${ }^{9}$, que funda Vasari (31 de enero de 1563), viene a sustituir y renovar, 250 años después de su fundación, lo que era una hermandad, o Compagnia di San Luca. Su intención era liberarla del espíritu del gremio de los oficios y reclamar el valor intelectual de la actividad artística, consciente de la evolución ya en su época de la condición social del artista ${ }^{10}$.

5 García Garrido, Sebastián, (2016) Artes Visuales hacia la transversalidad de la Cultura, la Educación y la Creatividad (discurso de ingreso), Málaga: Real Academia de Bellas Artes de San Telmo, pp. 33 y 34.

6 CENNINI, Cennino, (1821)Trattato della pittura messo in luce la prima volta con annotazioni del cavaliere Giuseppe Tambroni, manuscrito editado por primera vez en Roma.

7 En latín directrices.

8 Había venido utilizándose en textos especializados desde aquella época, como atestiguan numerosos documentos en el archivo de la Real Academia de Bellas Artes de San Fernando.

9 Meijer, B.W.-Zangheri, L. a cura di, (2015) Accademia delle Arti del Disegno. Studi, fonti e interpretazioni di $45^{\circ}$ anni di storia, Leo S. Olschki Editore, p. 3 y ss.

10 Este modelo académico tiene su eco en Nueva York, donde en 1863 se crea la National Academy of Design, pionera en EE.UU. para la formación en artes y diseño. 


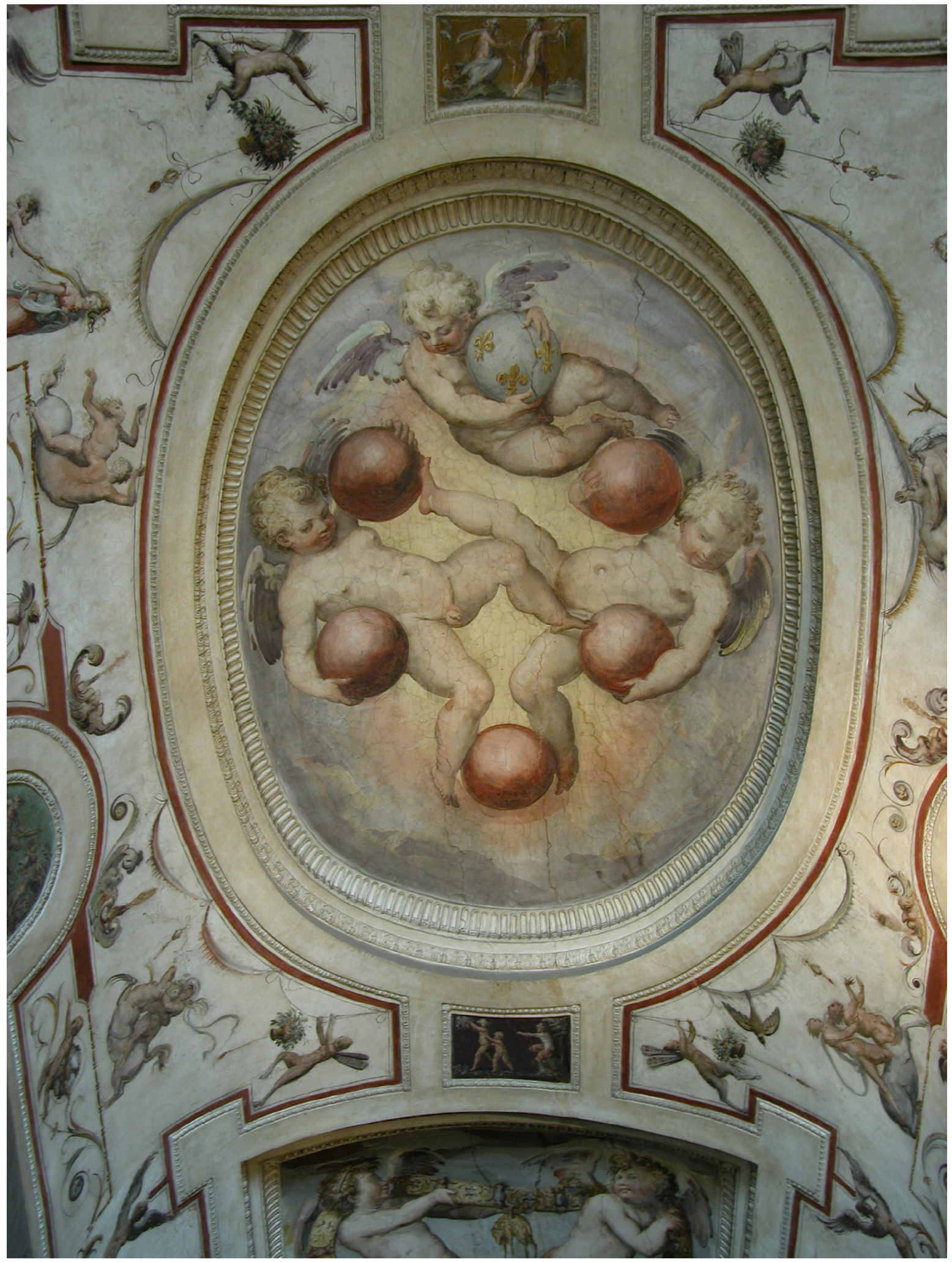

Fig. 1. Giorgio Vasari, diseño basado en el escudo de la familia Medici, para la bóveda de la cubierta de la escalera a las estancias privada del Palazzo Vechio, Florencia. 


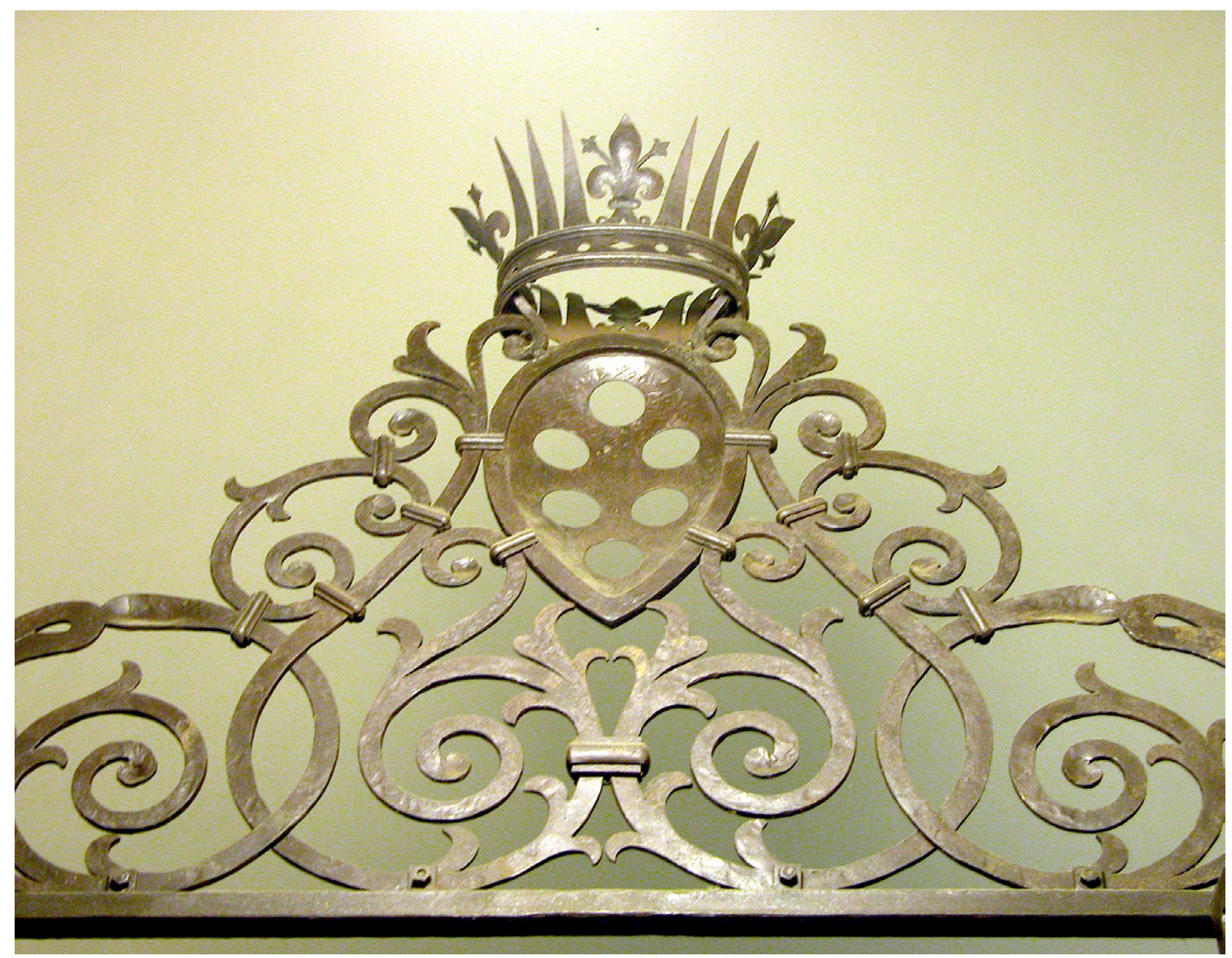

Fig. 2. Giorgio Vasari, diseño del escudo de Medici para realizar en forja en el patio principal del Palazzo Vechio.

Pero el diseño volvería a ser protagonista en los objetivos y necesidades de las Reales Fábricas, inicio de la producción industrial y verdadero precedente de la Revolución Industrial que, por el contrario, genera un industrialismo, en su dimensión positiva, con los objetivos de abaratar los costes y aumentar la producción mecánica y seriada. En las Reales Fábricas, creadas en los reinos en que gobernaba la dinastía de Borbón, se fomentaba la calidad del proceso en la asimilación de la destreza artesanal, y lograr un producto más asequible gracias a la cantidad de la reproducción seriada, para obtener unos productos que fuesen competitivos en mercados muy alejados del lugar de fabricación. Mientras, la interpretación en Gran Bretaña, en lo que se conoce como Revolución Industrial (finales del siglo XVIII a mediados del siglo XIX), de esas primeras fábricas provocaría el movimiento de reacción, en ese mismo lugar, conocido como Arts \& Crafts, que sin embargo venía siendo una realidad en las Reales Fábricas. Este movimiento, como sabemos, reclamaba la calidad y estética del producto, mediante la excelencia del oficio y el amor al trabajo bien hecho. En las Reales Fábricas, como centros de producción avanzada, permitían y se promueven normas igualmente adelantadas a su época, como era la igualdad de derechos entre hombres y mujeres, las infraestructuras oficiales para el cuidado de los hijos, y los comedores comunitarios para los trabajadores de ambos sexos, la asistencia y la correspondencia de los sueldos con la especialización y calidad del trabajo que cada uno realiza a pesar 
de la igualdad social externa, reflejada en que todos vestían con un mismo modelo generalizado. Uno de los casos más relevantes fue la Real Fábrica de la Seda de San Leucio (1766), en los alrededores de Nápoles y ubicada en uno de los palacios de los reyes, donde destaca que se incorporasen todas las fases del producto, desde la cría del gusano que produce la seda, el proceso de la fibra, el diseño y la fabricación. A ello se une un avanzado precedente de lo que sería la Publicidad, aunque se considere que nace de modo generalizado alrededor de 1880. El salón de baile y banquetes de ese palacio de caza, que seguía frecuentando la familia real para supervisar directamente, identificados y comprometidos, el avanzado sistema productivo, se llegó a denominar Sala de la Publicidad porque en él se recibía a los mandatarios y comerciantes de todo el ámbito potencial de clientes europeos, para mostrarles los productos realizados. Incluso se proyecto una utópica ciudad industrial de planta circular, por Francesco Collecini, discípulo de Luigi Vanvitelli.

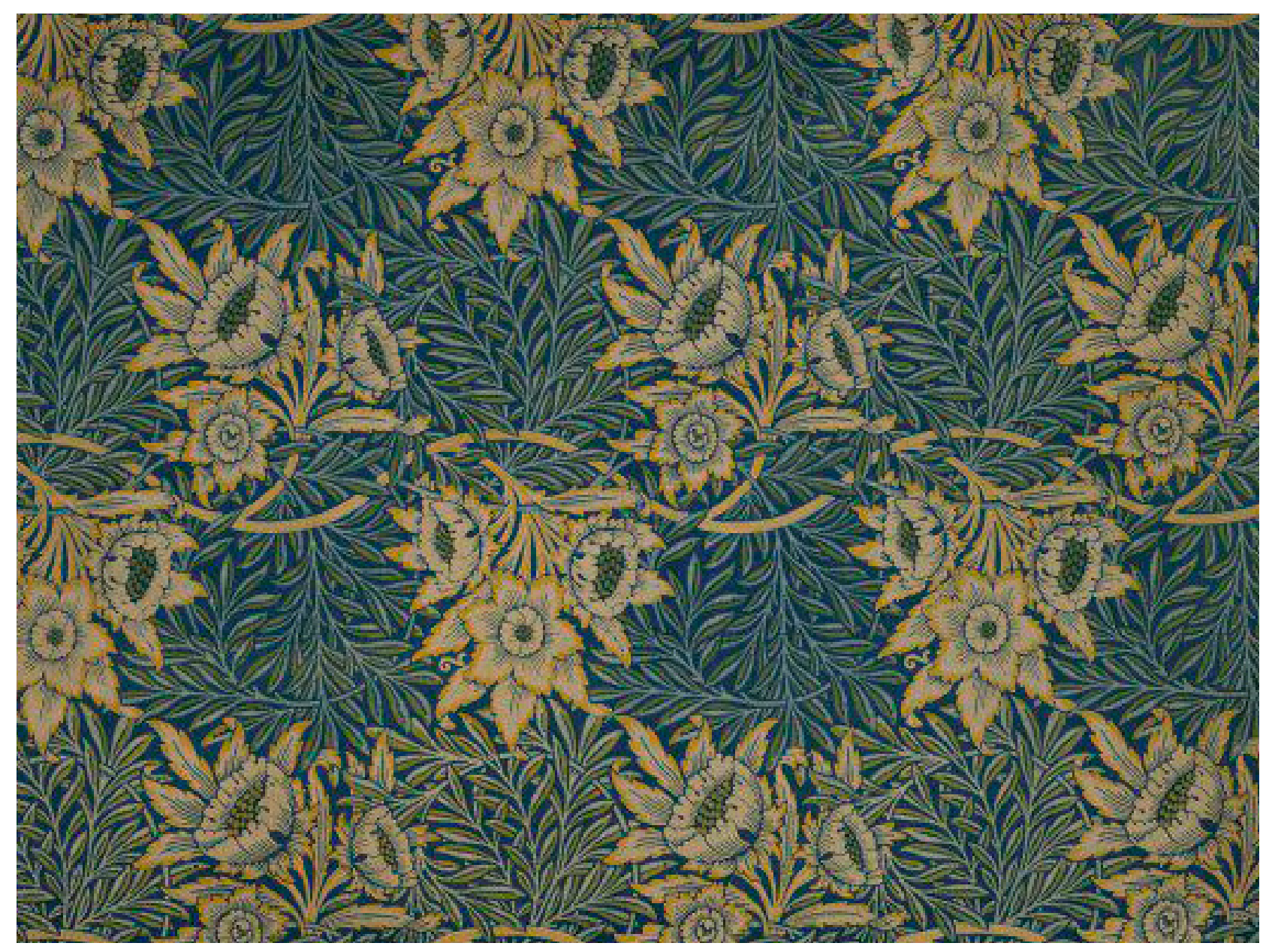

Fig. 3. Tulip and Willow, diseño para papel pintado, de Williams Morris, 1873. 


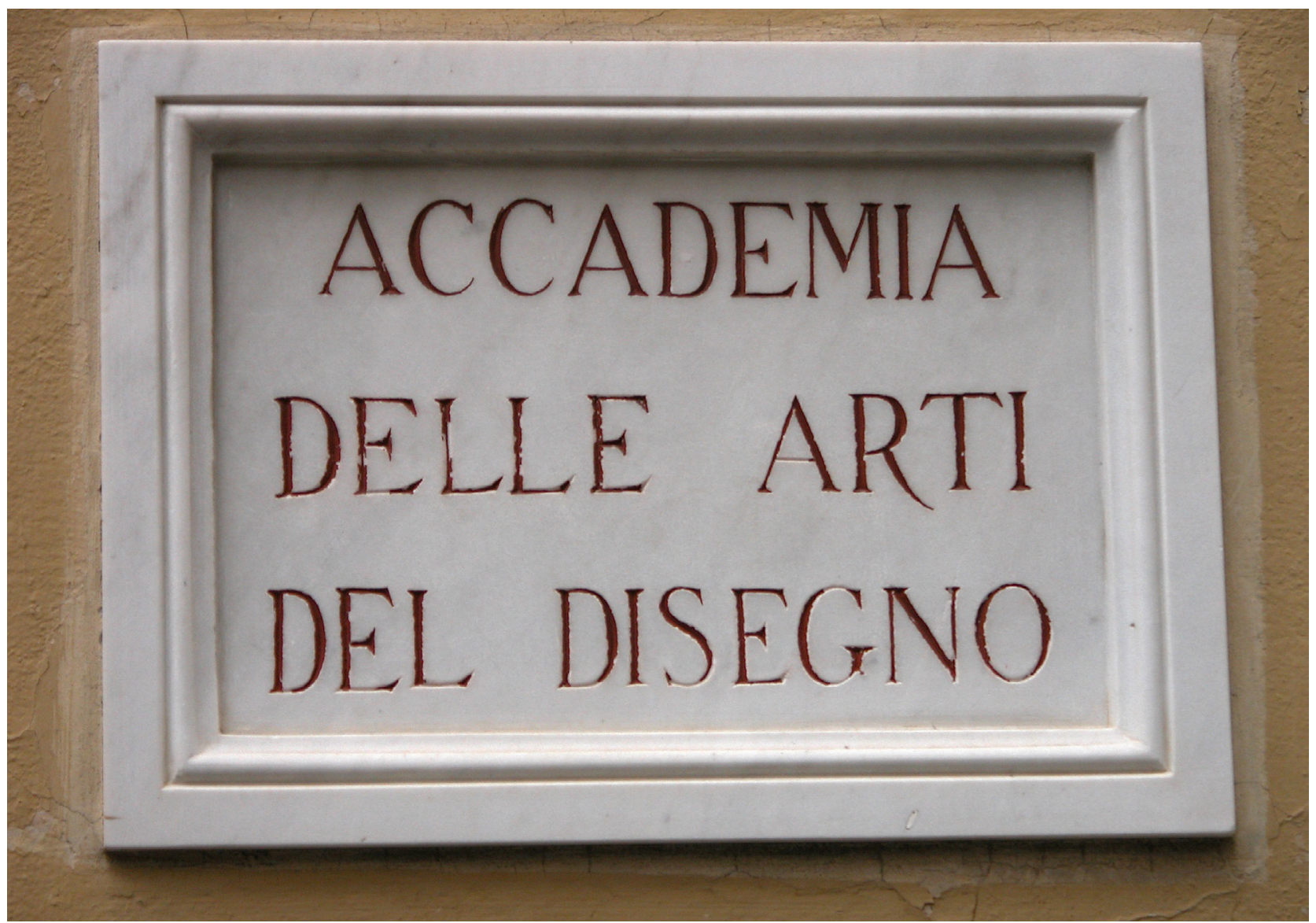

Fig. 4. Rótulo original en la fachada de la antigua sede de la Accademia delle Arti del Disegno en Florencia, 1550.

\section{El diseño ante el reto de la industria}

El diseño es una prioridad en este nuevo concepto de real fábrica, promovida por el estado para fomentar una actividad estratégica para el desarrollo del país, e innovadora, que diera lugar a que se reprodujera el modelo por parte de la iniciativa privada, como podrían ser las que emprendieran algunos de sus trabajadores. El producto, de la máxima calidad en cuanto a material y manufactura, hecho en serie para abaratar costes mediante la tecnología más avanzada en ese momento, se revalorizaba y obtenía garantía de éxito en el mercado si tenía un diseño que lo sustentara. Esta necesidad de nuevos profesionales, pues el diseño quedaba en manos de la capacidad creativa de los propios artesanos, se entendió en la política de desarrollo emprendida por Carlos III y, mediante Real Cédula, crea la Escuela Gratuita de Diseño ${ }^{11}$, en Barcelona, Zaragoza y Madrid, que serían el precedente de las posteriores Escuelas de Artes y Oficios Artísticos. En este decreto el diseño se equiparaba con disciplinas, tan relevantes entonces, como la Navegación, el Comercio o la Política. El calificativo de 'gratuita' acercaba el acceso a la cualificación profesional a trabajadores que no contaran con medios ni posibilidad de dedicarse a su formación, puesto que en este ámbito se consideraba que el potencial creativo del diseñador tenía una buena proporción de cualidades innatas. En este documento oficial de creación de la que sería primera escuela de diseño en el mundo, que trascendería el concepto del 
dibujo y el disegno renacentista, se define en esa época la actualización que correspondería a ese término empleado únicamente en ámbitos muy especializados. Diseño se define como "la adecuación del dibujo a las exigencias de la producción mecánica y seriada, sin descuidar el buen gusto y el espíritu creador"'12. Éste sería el hito que recupera el término y rehabilita el concepto forjados por la conjunción de grandes artistas en el Renacimiento.

\section{Especialización académica y cualificación profesional}

Mientras no existe una formación especializada y de alto nivel, y una serie de títulos oficiales en un disciplina determinada, no tenemos diseñadores propiamente dichos. A colación con ello, se dice que no existe una profesión, claramente reconocida, mientras no existe una revista especializada.

Sin embargo, el concepto de Diseñador, en el campo que nos ocupa, agrupa cualquier tipo de manifestación del diseño: bidimensional, tridimensional de productos y de espacios, analógica o digital, estática o animada... Todo esto en el marco del diseño estratégico global que el diseñador debe resolver como sistema eficaz de comunicación, mediante conceptos y mensajes, tanto materiales como intangibles.

El diseñador es intérprete del sentido institucional y de la personalidad de la empresa; es también estratega para orientar su trabajo con la más acertada intencionalidad; y es comunicador, por cuanto su trabajo consiste precisamente en transmitir e implantar una identidad en la mente del público. El diseñador debe ser, además, una persona que se comunique bien y que tenga sentido emprendedor. Debe pensar en marketing (...) Debe estar muy atento en lo que concierne a su cliente, para entenderle y poder interpretarle. Atento también a lo que se refiere al público, a los públicos que son los destinatarios de su trabajo. Y por supuesto, atento al entorno de señales, signos, símbolos e imágenes, en el que su trabajo debe insertarse. El diseñador no tiene que imitar a nadie, sino dar su interpretación personal y profesional a los problemas que se le presentan. Tiene que observar el mundo y leer de todo"13.

En el actual mercado globalizado, la función que viene a desempeñar el diseñador en la sociedad no es ya la de "solución de problemas", sino la de crear "propuestas innovadoras que propongan nuevos enfoques, estrategias, productos y servicios y que permitan a las empresas e instituciones, iniciar esfuerzos proactivos de desarrollo y no sólo reactivos de supervivencia"14. La actividad del diseñador y del equipo de diseño no se limita al periodo necesario para proyectar cualquier tipo de necesidad que demande la organización, sino que está próxima a lo que sería un grupo de investigación permanente. Ese equipo debe observar tendencias en el ámbito de la empresa, y emprender soluciones futuras que a veces es necesario archivar hasta que el mercado demande esa opción, con resultados competitivos. Pero ese ir por delante de las necesidades del mercado es lo que diferencia a una empresa competitiva de otra dedicada a intentar compensar apresuradamente las novedades que ofertan los líderes en el sector.

Aumenta la tendencia de construir una identidad cultural comprometida con los valores del destinatario de nuestros productos. Al mismo tiempo que esta imagen del servicio se cuida cada día más, en las estrategias

12 Libro de Acuerdo de la Junta (Nacional) de Comercio, 30 de marzo de 1775, p. 248. Ruiz Ortega, Manuel, (1999) La Escuela Gratuita de Diseño de Barcelona 1775-1808. Barcelona: Biblioteca de Cataluña.

13 COSTA, J. Imagen global op. cit. p. 97.

14 Lecuona, Manuel (2010) Diseño estratégico. Guía metodológica, Gijón: Fundación Prodintec, p. 16. 
de comunicación de la empresa, los profesionales del diseño deben comprometerse al mismo tiempo con la sociedad para la que trabajan, buscar soluciones más adecuadas a un desarrollo sostenible, más respetuosas con la diversidad cultural y social, etc. En todo este panorama, que está presente en gran parte de los foros del ámbito del diseño y el marketing, encontramos desde posturas abiertamente comprometidas hasta otras más discretas. Cada vez se tiene más concienciación y "servir mejor a la sociedad se ha convertido, nuevamente, en una preocupación central en el discurso actual del diseño"15. La empresa, finalmente se ve renovada, en su imagen y en su necesidad de emitir mensajes visuales e intangibles, si éstos al mismo tiempo van eliminando prejuicios pasados.

Estamos ante lo que se denomina diseño estratégico, en cuanto a un sistema integrado de difusión y promoción de una serie de valores que pueden orientarse a las necesidades tangibles e intangibles de una marca en el mercado, o bien a una serie de valores personales y sociales que se requiere fomentar y promover o cambiar conductas y comportamientos poco cívicos en cualquier aspecto.

El diseño es responsable de que todas las manifestaciones de la empresa sean coherentes con su proposición estratégica, para que se refuercen entre sí y que de esta forma se optimicen los recursos invertidos y mejore su competitividad. Desde una concepción más avanzada, sin embargo, el diseño no tiene categorías ni etiquetas, sino que es global: del mismo modo en que el producto trasciende lo físico para abarcar una oferta conjunta de bienes y servicios, el diseño transciende el objeto y conquista territorios intangibles que antes le estaban vedados, como son la interacción, los servicios o la experiencia, todo aquello que envuelve, cualifica, diferencia y posiciona un producto avanzado [...]

Los expertos en gestión se han dado cuenta -con cierta sorpresa- de que éstas son las habilidades básicas que se requieren en la empresa para desenvolverse con solvencia en el complejo mercado de hoy y, de esta forma, el diseño está empezando a capitalizar una nueva misión estratégica en el ámbito de la gestión a través de lo que se ha dado en llamar design thinking (o pensamiento de diseño) y que está siendo adoptado por las organizaciones punteras en todo el mundo.

El fin último del diseño es la mejora de los productos y procesos para una mayor satisfacción de las personas y una mejora del bienestar de la sociedad en general ${ }^{16}$.

En cuanto al diseño de la metodología del proyecto, la primera premisa que se debe considerar, en cualquier proyecto de diseño contemporáneo, es que no existen dos proyectos iguales. En consecuencia, pretender aplicar las mismas directrices y planteamiento general a dos proyectos, por muy similares que aparenten ser, tiene las mayores posibilidades de que resulte un fracaso. Cada proyecto debe, por tanto, diseñar previamente su propia metodología.

En cuanto al diseño de la metodología del proyecto, la primera premisa que se debe considerar, en cualquier proyecto de diseño contemporáneo, es que no existen dos proyectos iguales. En consecuencia, pretender aplicar las mismas directrices y planteamiento general a dos proyectos, por muy similares que aparenten ser, tiene las mayores posibilidades de que resulte un fracaso. Cada proyecto debe, por tanto, diseñar previamente su propia metodología.

\footnotetext{
15 PELTA, R. op. cit. p. 87.

16 Viladàs, Xènia (presentación), en Lecuona, M. (2010) op. cit, pp. 10-11.
} 
El factor cultural será el decisivo hilo conductor de cualquier proyecto, cuya identidad y trascendencia se ha dejado patente en diferentes capítulos. "El diseño es una práctica con profundas raíces culturales, que puede ser categorizada como una forma artística ${ }^{17} \mathrm{o}$ artesanal ${ }^{18}$. Representar al diseñador como un artesano otorga un reconocimiento mayor al saber del diseñador: "Los diseñadores están inmersos en su cultura material y crean formas basándose en ellas como fuente primaria de inspiración. El diseñador tiene la habilidad de leer y escribir en su propia cultura"19. "El Thinking del Design Thinking no es un método, es una huella profunda de su educación y experiencia. Los métodos del diseño son solo la parte superficial del proceso, es el contenedor en el que el pensamiento tiene lugar"20.

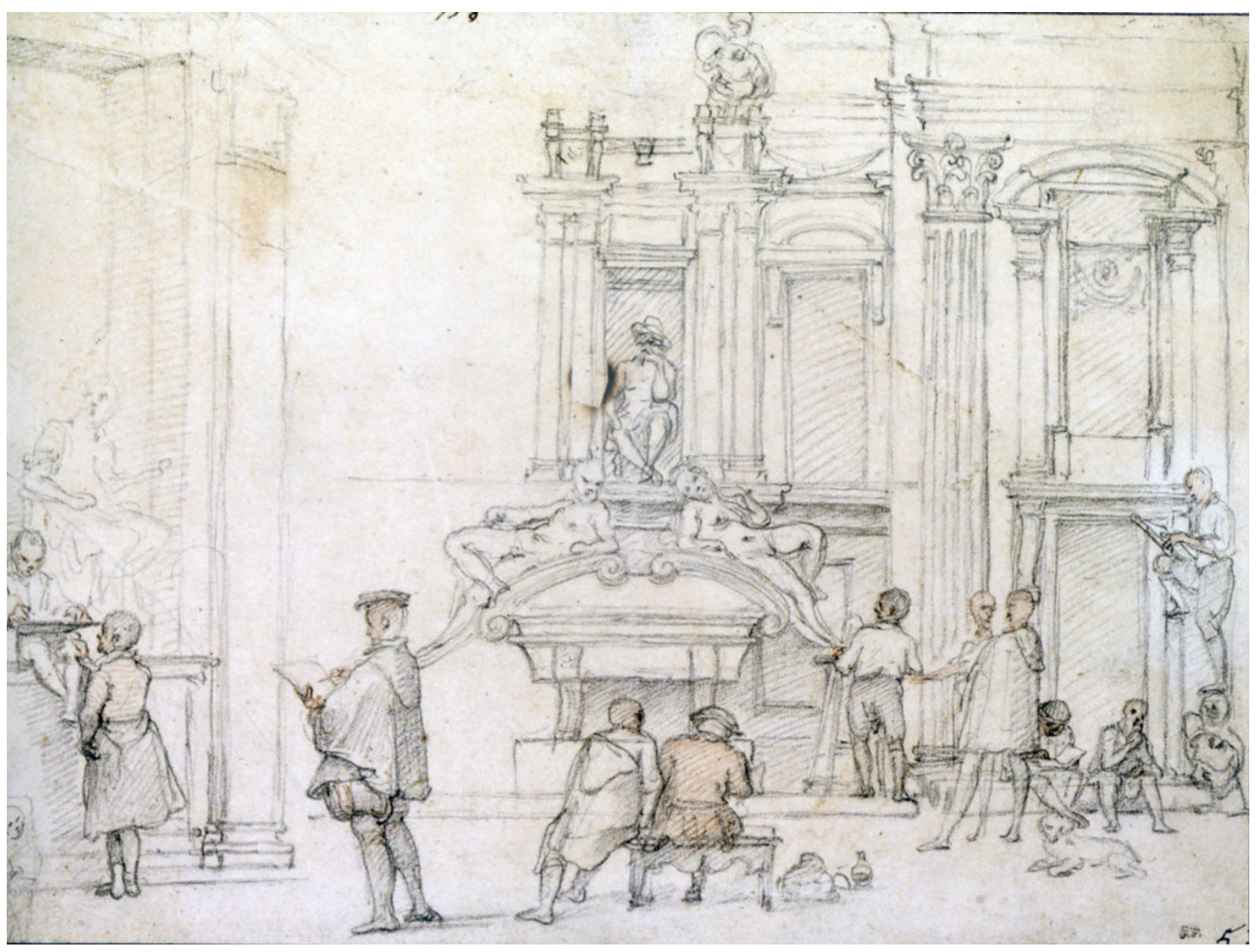

Fig. 5. Federico Zuccari, dibujo de los alumnos de la Academia del Diseño dibujando en la Sacristía de San Lorenzo, Florencia siglo XVI.

17 SCHÖN, Donald, (1983) The Reflective Practitioner, How Professionals Think in Action, Nueva York: Basic Books.

18 SENNETT, Richard, (2008) The Craftsman, New Haven: Yale University Press.

19 CROSS, Nigel, (2007) Designerly Ways of Knowing, Basilea: Birkhaüser.

20 GARDNER, Edwin, (2014) “Design Thinking $\neq$ Design Thinking”, en JARAUTA, Francisco y MEDINA, Pedro (eds.), Cuadernos de Diseño 4: Diseño de procesos, Madrid: Editorial IED. 
El propio Design Thinking que promueve Nussbaum como recurso para renovar y potenciar el diseño, rompiendo moldes para llegar a resultados entonces inesperados, es asimismo motivo de renovación. Él mismo afirma recientemente que el "Design Thinking es un experimento fallido" $y$, a su vez, comienza definiendo una nueva estrategia de diseño; la "Inteligencia Creativa", que consiste en aprovechar el poder de crear, conectar e inspirarse ${ }^{21}$.

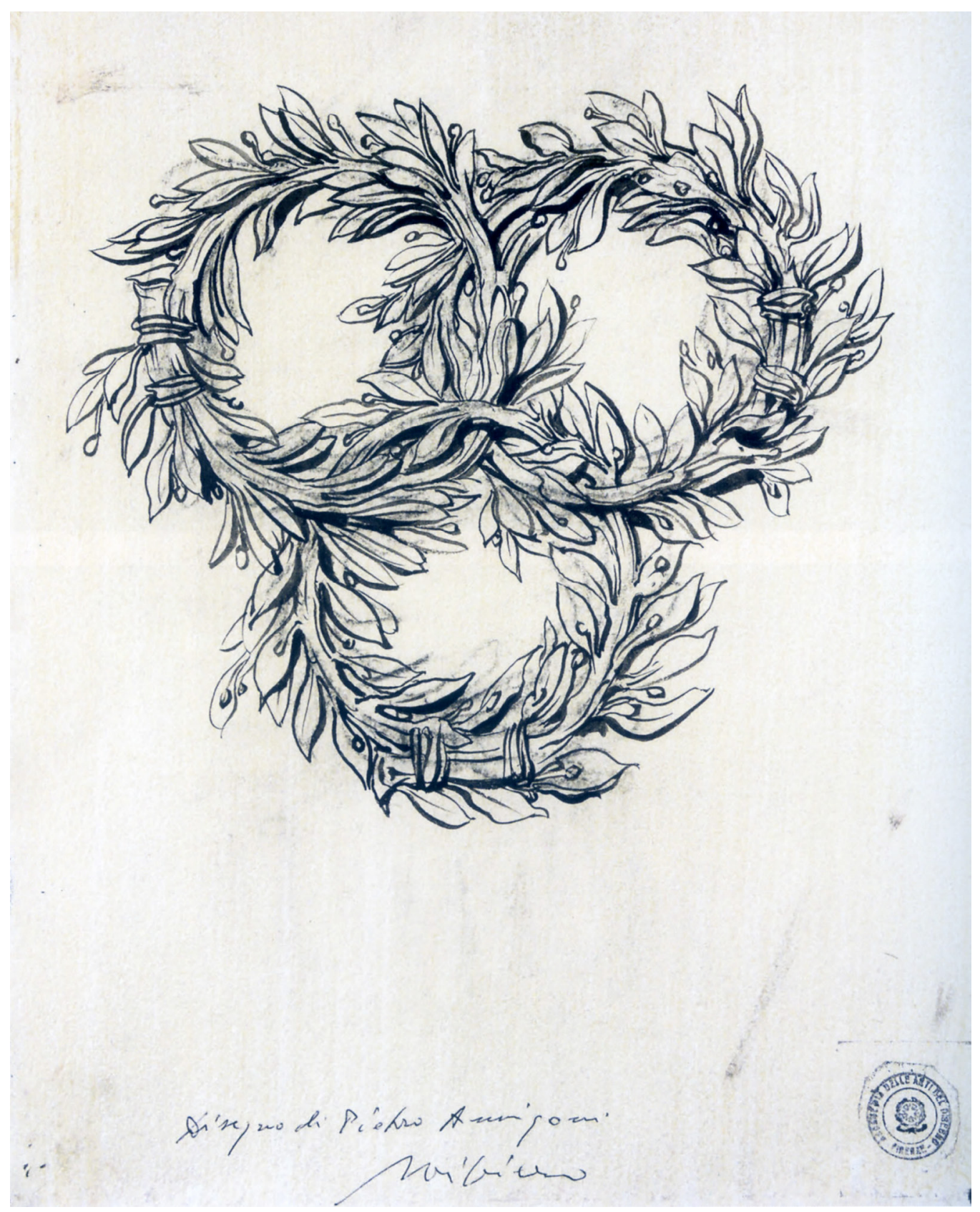

Fig. 6. Pietro Annigoni. Símbolo de la Accademia degli Arti di Disegno, como fundamento de las tres nobles artes. 


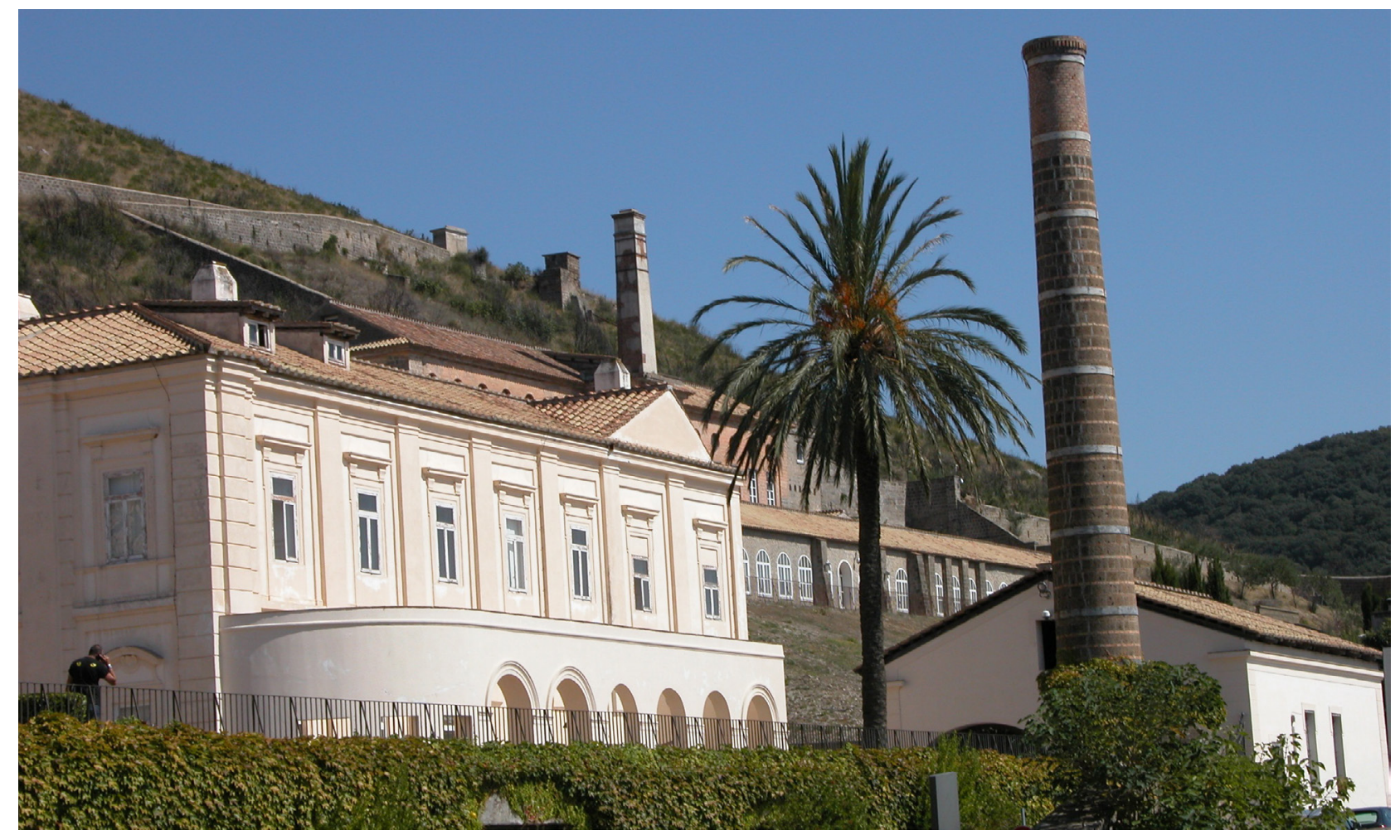

Fig. 7. Real fábrica de la Seda, en el Palacio Real de San Leucio, cerca de Nápoles.

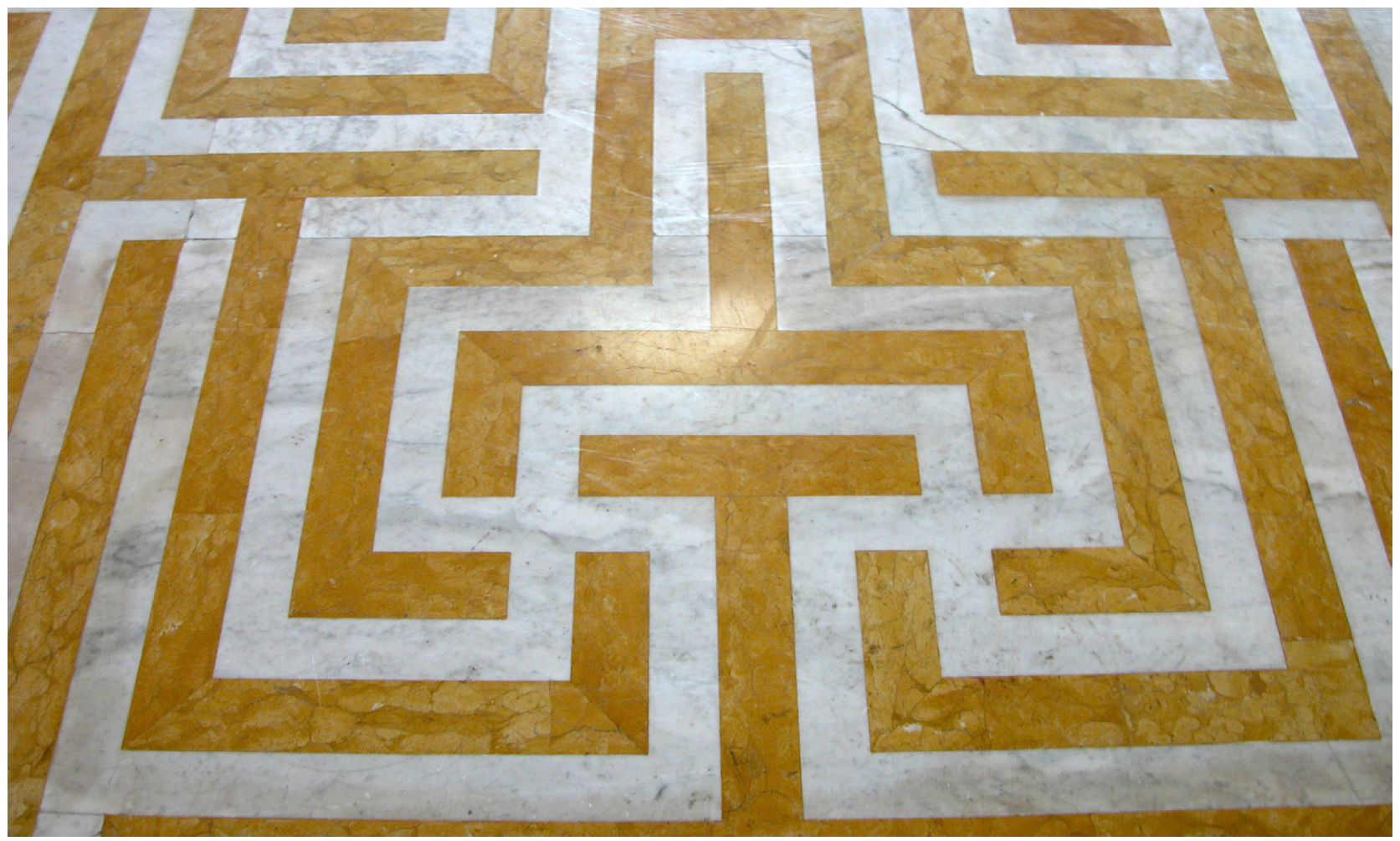

Fig. 8. Pavimento para el Palacio Real de Caserta, realizado en el Real Laboratorio de Piedras Duras de Nápoles. 


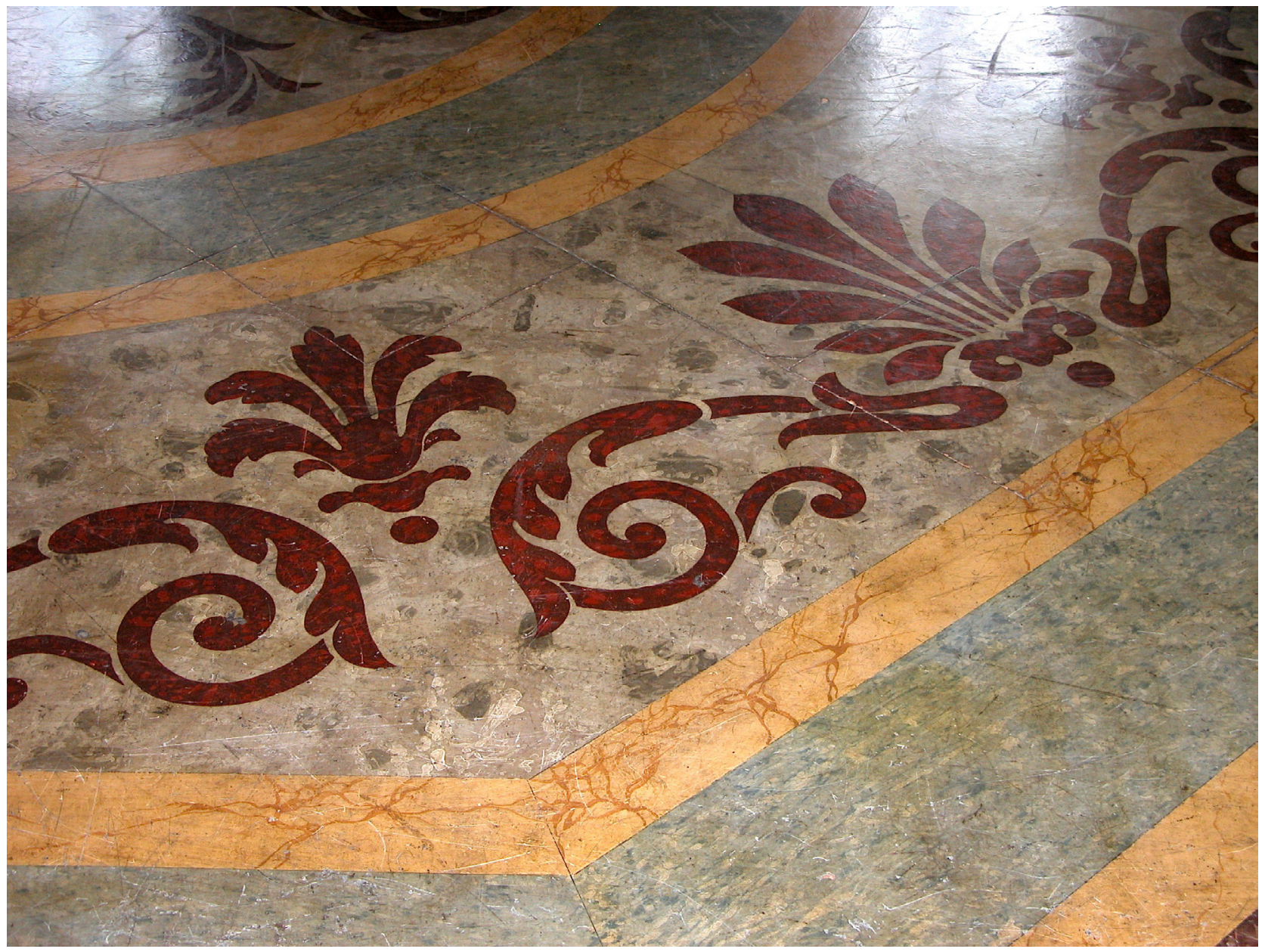

Fig. 9. Motivos en mármol del Palacio Real de Caserta, realizado en el Real Laboratorio de Piedras Duras de Nápoles. 